\title{
LEARNING FROM THE INTEGRATED CURRICULUM APPROACH: STUDENT REFLECTIONS DURING AND AFTER THEIR EXPERIENCE
}

\author{
Yani Jazayeri, Robyn Paul, Laleh Behjat, and Mike Potter \\ Schulich School of Engineering, University of Calgary \\ spjazaye@ucalgary
}

\begin{abstract}
At the University of Calgary, we piloted an integrated curriculum approach in second-year electrical engineering. The intention was to provide authentic learning experiences, with the ultimate goal of fostering deep learning in the students. To improve students' learning strategies, they were asked to reflect weekly on their learning during the program (Winter 2019: Jan-Apr), and during their first semester of third-year, which was run in the traditional format (Fall 2019: Sep-Dec). Using qualitative coding, these reflections were analyzed with a framework from self-determination theory to understand the student learning and motivation throughout the program. There were 11 themes that emerged, categorized within the three elements of the theoretical framework: competence, relatedness, and autonomy.
\end{abstract}

Keywords: integrated curriculum: electrical engineering : student reflections

\section{INTRODUCTION}

The Engineering profession is complex and interdisciplinary, and students today must learn how to integrate skills across technical and social disciplines. However, most university academic programs are siloed with content broken down to individual courses with limited, if any, intentional linkages between these courses. It is not until the end of most engineering programs that students are expected to do a Capstone design project, which is the first time they will be required to integrate their four years of technical knowledge. At the University of Calgary, we piloted an integrated curriculum approach in the second-year electrical engineering. This paper provides a brief overview of the approach and an analysis of the students' reflections. The self-determination theory of motivation [12] provides a framework for understanding the impact on student learning within the integrated curriculum.
Integrated curriculums can be defined as the approach to teaching content from two or more domains, "within an authentic context for the purpose of connecting these subjects to enhance student learning” [7]. The integrated curriculum approach shows improvements across many factors: faculty development and collaboration; retention and diversity; learning of disciplinary content; and acquisition of non-disciplinary skills $[5,10]$. These come with large-scale curricular challenges, as often integrated curriculums require fundamental changes in instructor and institutional practices and beliefs [2,5]. Additionally, although there is evidence to support improved learning in integrated curriculums, learning of the material must still be scaffolded: "connecting ideas across disciplines is challenging when students have little or no understanding of the relevant ideas in the individual disciplines” [9].

In the winter term of 2019, at the University of Calgary, we implemented a pilot project for second-year electrical engineering where a group of 34 students were taught all five of their courses in an integrated format. The intention was to provide authentic learning experiences, with the ultimate goal of fostering deep learning in the students. In order to facilitate some of the challenges regarding the integration, several techniques were incorporated into the course. We grouped students into learning communities and developed several team building activities to build a sense of community. The teaching was further integrated by having the students work on real-world projects during the semester that required them to combine concepts from across the five traditional Electrical and Computer Engineering courses.

To improve students' learning strategies, they were asked to reflect weekly on their learning during the program (Winter 2019), and during their first semester of third-year, which was run in the traditional format (Fall 2019). Using qualitative coding, we analyzed these reflections using a framework from self-determination theory [12] to understand the student learning and motivation throughout the program.

This paper provides insight into the student learning experience in an integrated learning curriculum in second- 
year electrical engineering. We also provide the wider community with an understanding of how they could implement something similar at their own institution.

\section{INTEGRATED CURRICULA}

Engineering industry is in its nature heterogeneous, and when our students graduate, they must be able to synthesize a wide variety of skills in the workplace. This integrative nature of the engineering industry means our engineering curricula should also be promoting "integrative, synthetic thought processes" [5]. Rather than hoping that our students can make the connections between the content and real-world applications, an integrated curriculum approach intentionally provides the contextual connections for students during their learning process [7].

\subsection{Types of Integrated Curricula}

A survey of researchers using "integration” in the 2003 ASEE publications found different intentions and meanings. The findings ranged from integrating a single topic into a course, to integrating concepts like biology into the engineering curriculum, to full integration across disciplinary boundaries [5]. Others have defined integrated curriculum as individual courses working together requiring them to be "interdependent upon one another and bound by a common thread of knowledge” [3]. The goal of integrated curriculum goes beyond crossing the boundaries of domains to also providing "an authentic context for the purpose of connecting these subjects to enhance student learning” [7].

Fogarty provides an interesting analogy to different approaches to integrating curriculum [4]. He makes effective use of analogies, such as the traditional curriculum which is the fragmented model, like a "periscope" where we have a single, narrow focus on one discipline as a time or the sequenced model which his more like a pair of "eyeglasses" where there are separate lenses connected through a common frame. For the purpose of this paper, we believe our approach fits the connected model which is like the "view through an opera glass, providing a close-up of the details, subtleties, and interconnections within one discipline” [4].

\subsection{Benefits of Integrated Curricula}

Two theories from the science of learning can help us to better understand the value of integrating student learning experiences. Firstly, situated cognition theory states that understanding the application of knowledge and skills is as important as understanding the knowledge and skills themselves [7]. This theory underlines the importance of the learning process including contextual information. Secondly, based on functional MRIs, we know that to remember new information our brain must make connections with existing knowledge [5]. For our students, this means that if we can integrate our content, we are creating stronger pathways by continuously teaching new information by relating it to old information.

Integrated curricula have been practiced in some engineering schools for the past 30 years. This pedagogy shows improvements in student learning of engineering content; fosters the development of nontechnical engineering skills; increases retention in engineering; decreases student workload; encourages faculty collaboration; and increases social connections. For example, retention rates increased by $15 \%$ in Ohio State's integrated first-year curriculum, and by $20 \%$ in Alabama's program [5]. Some universities have also shown improved time to completion for students in the integrated curriculum, such as at Drexel and Texas A\&M programs. There is also evidence that integrated curriculum appeals to a broader audience, where often greater rates of retention and improvements are seen in women and other excluded minorities [5].

One group of authors found three main advantages to the integrated programs [3]. First, it provides motivation and encourages more meaningful learning experiences for students by introducing content that is interdependent, so students understand the value of what they are learning. Second, it allows faculty to have better control of the curriculum, where holistic approaches to curriculum content promotes less repetition and concepts can be more easily tied together. Lastly, framework is easier to develop for students where the curriculum supports them in attaching knowledge to previous knowledge, rather than presenting disjointed material across courses where students need to develop their own knowledge frameworks [3].

\subsection{Challenges of Integrated Curricula}

As with any great pedagogy, there are challenges with implementing an integrated curriculum. Firstly, it is a large scale curriculum change which comes with challenges and road bumps. To mitigate these, often a pilot project will be run first, however a successful pilot project does not guarantee the same results and success institutionally [5]. It is important to move towards the large-scale change with a strategic, multi-year approach in order to ensure effectiveness.

Faculty participants can create other challenges. They often perceive that nothing can be changed or removed in a curriculum, and a more open-minded approach is necessary. Integrated curriculum requires a fundamental change in practice and beliefs of the faculty members, and they may be resistant to the amount of flexibility required [3]. Additionally, "making cross cutting STEM connections is complex" and faculty, although experts, may find it challenging to make interdisciplinary connections between material that they are used to segregating into course structures [7].

Lastly, it is also important to note that although integrated learning is more effective, that does not mean 
students will not have challenges. Specifically, "connecting ideas across disciplines is challenging" especially when students "have little or no understanding of the relevant ideas in the individual disciplines" [6]. The integration process needs to be scaffolded for the students, as they need to reconsider their own ideas about learning and knowledge development.

\subsection{Learning Community in Integrated Curricula}

Many authors on integrated curriculum discuss how social connections are often not the primary intention, however the community of learners developed from the integrated learning method greatly enhances the learning experience. One of the key outcomes of integrated learning is that "teachers and students need to work cooperatively in the educational process to ensure successful learning” [8].

Due to clustering of students in small groups, active learning, and project-based learning are typically used in integrated curricula. In this environment, students naturally form strong learning communities. These learning communities "help learners build interdisciplinary links and social links within a community" [5]. This applies both to students, and to the faculty involved who must collaborate to plan, design, and implement the curriculum.

In these communities, along with the relationships built with the instructors, novice and experienced practitioners learn from each other, "observing, asking questions, and actually participating alongside others with more or different experience” [7].

Although the learning communities are valuable, it is important to keep in mind that social settings are not conducive to learning for everyone. Engaging in this social environment may be difficult for some students, limiting their ability to effectively learn with this approach [7]. Some research however has shown that learning communities can be particularly effective for women and minorities in improving their persistence through a program [5].

\section{CONTEXT: INTEGRATED LEARNING STREAM}

In this section, we provide an overview of the Integrated Learning Stream (ILS) that was implemented in Winter 2019 at the University of Calgary.

\subsection{Scheduling}

All activities for the set of 5 courses - lectures, labs, projects, tests, etc. - took place in one room. The room had several workbenches, with worktables at them, that can easily double-up as both studio tables and spots for practical exercises. The room was secured for the entire term, all day, every day so it was effectively the students' home. The ILS provided the students with the same technical content as the regular Electrical Engineering program, but in an alternative way.

\subsection{Design Project and Hands-On Exercises}

A major component of the ILS is the design project, which was a digital audio player for 2019. Student were organized into 3-4 person project teas for this component of the course. The technical courses that run in the first 89 weeks of the ILS have a series of hands-on exercises where students built components of a basic version of the audio player. For example, they learn how to design the electronics to drive the speaker and control volume as part of their circuits course (ENEL 343). As part of this course, the students learn circuit parameters, RC, LC and RLC circuits as well as filters. The students learn how to program the microcontroller as part of the computer organization course, ENCM 369. They build a power supply as part of the electronic devices and materials, ENEL 361. The students work on understanding the analysis of the input and output signals as well as the mathematical modeling of the whole system as part of the Signals and Transform course, ENEL 327. Finally, the students learn Agile project management, teamwork, entrepreneurship and innovation as part of the project course, ENEL 300. At the end of the first 9 weeks, every group has built a fully functional but very basic audio player.

During the term, the students also work on using this audio player as a platform to solve a real-world problem. An example problem would be developing an audio teaching tool for autistic students. Working in teams, students extend their basic audio player and add new features aimed at solving the design problem.

\subsection{Flow of the Semester}

The five courses that comprise the traditional semester consist of four technical courses, along with one project/design course. Normally these are taught in parallel to each other, on a regularized weekly schedule, with the project course being delivered alongside the other four courses. Also, the project in that course is not normally linked to the other four courses at all. The format of this normal semester is indicated in Figure 1(a).

In the ILS, the project course is linked to the content from the other four courses. In order to succeed in that project, students need to master components of the other courses first. To allow for this, the semester schedule takes on the format indicated in Figure 1(b). In the middle block of the Integrated Learning Semester, the content of the four technical courses is delivered in a condensed fashion. 


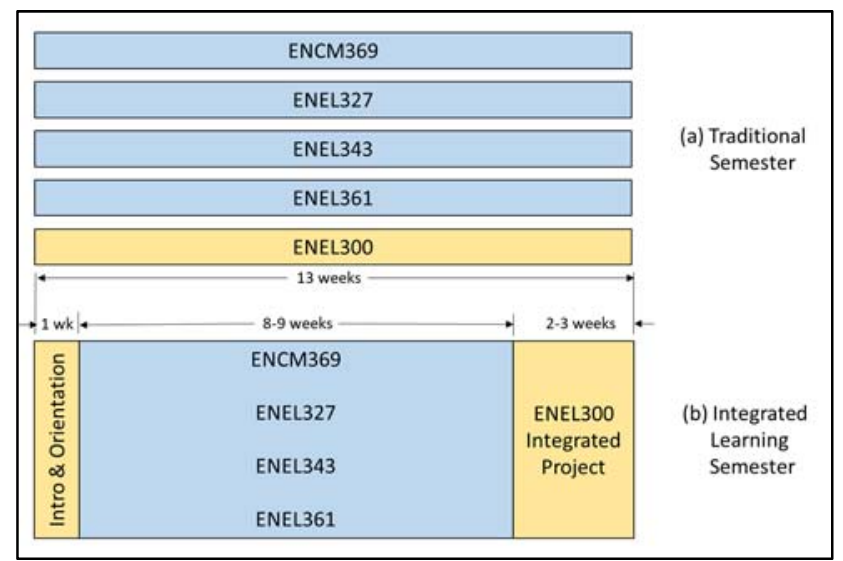

Fig 1. Semester Timeflow (a) Traditionally; and (b) in the ILS.

\subsection{Flow of the Semester}

One benefit of having a space that is fully controlled by the program is the ability to be very flexible with when and how the material is delivered over the semester. Example schedules for two consecutive weeks are provided in Figure 2. This allows the instructors to integrate material between courses by e.g. having a hands-on activity that merges ENEL343 and ENEL361 content. It also allows them to, for example, lecture for 30 minutes about a topic, followed by 30 minutes of hands-on work to demonstrate that concept in practice, before returning to some discussion about it.

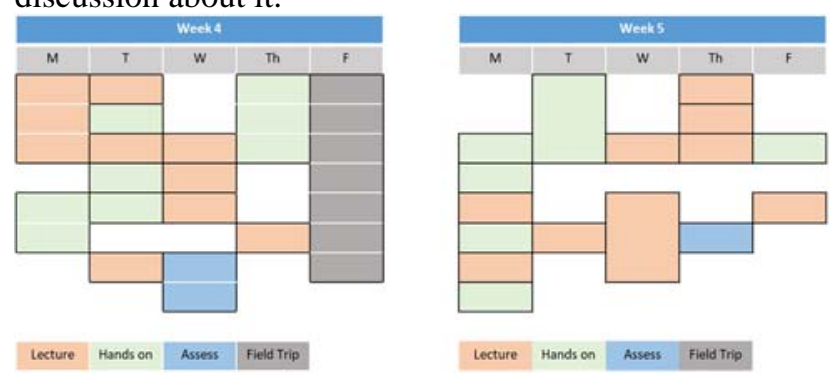

Fig 2. Flexible weekly schedule

\subsection{Delivery Approaches}

There are a variety of approaches used by the instructors for delivering the content to the students. Some lectures and hand-on experiences are more traditional, while others may heavily integrate moments spent in discussion and lecturing along with quick hands-on demonstrations or exercises to reinforce that content. Some of the instructors use a flipped classroom approach.

\subsection{Student Assessment}

As part of the assessment practices in the ILS, students learn how to assess their own learning, how to plan to excel in their studies, and how to seek support in their learning journey. Because of the integrated project, the instructors can assess not only the students' knowledge and comprehension of subjects, but also their ability to evaluate design choices and their creativity in design.

Assessment in the ILS has several different aspects. One part of the assessment is focused on individual achievements of the students while other parts are focused on the group work. One important difference is that there will be some assessment pieces where the assigned grade may contribute to more than one individual course. For example, when the students build the amplifier for the audio player, their grade for the demonstration of that component may contribute to both ENEL361 and ENEL343. In the design course, ENEL 300, an agile project management style is used. The length of each sprint is 3 weeks. At the end of the three weeks, the students showcase their potentially shippable product, and documentations showing their understanding and implementation of the design and project management concepts. All of these documents are assessed to show the students how their products and their process would fare it were the end of the class. This assessment provides an opportunity for the students to use the assessment for furthering their learnings, instead of seeing it as a ranking or measuring instrument.

Figure 3 helps build a mental picture of assessments in the ILS, where one possible modality for assessment for each of the five courses in the semester has been sketched out. Each individual course has occasions for an assessment piece that contributes only to that course (A); this might be a quiz, a writing piece, or a presentation. There are also pieces that assess the learning outcomes for two or more courses (B); e.g. the design, construction, demonstration, and testing of an audio amplifier that is evaluated ENEL343, ENEL361 and ENEL300. Finally, there are pieces that assess students on something that contributes to all five courses (C); this might be most related to the design project.

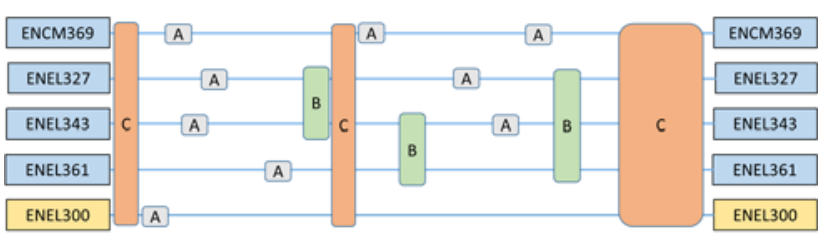

Fig 3. Assessment visualization

\subsection{Reflections as Self Assessment}

At regular times throughout the semester, students perform a self-assessment (Reflections) where they explore strategies that helped them learn well (e.g. "I took the time to thoroughly watch the videos and to understand the prelab"). They also consider strategies that were not successful (e.g. "I need to get more sleep"). Based on these reflections, students decide on action items that can help them with improving their learning outcomes. These selfassessment tools are based on those developed for highperformance Olympic athletes, and the instructors believe 
that these not only help students with learning the material during the term, but also with becoming life-long learners.

\section{METHODOLOGY}

\subsection{Theoretical Framework: Determination Theory \\ Self-}

Motivation was chosen as the theoretical framework for evaluating the success of the ILS program for one simple reason: "motivation produces" [12]. The goal of the ILS program is to support students in their learning so they can achieve more in their academic and professional careers. Thus, motivation is an appropriate tool for measuring this.

There are many theories on motivation, from needsbased theories such as Maslow's hierarchy of needs, to process-based theories such as expectancy and reinforcement theories [13]. In educational settings however, it has been found that the use of selfdetermination theory (SDT) is productive as it provides guidance on the environment a teacher can foster to support student motivation [11].

Ryan and Deci are the primary thought leaders behind SDT, and they describe it as "an approach to human motivation and personality that uses traditional empirical methods while employing an organismic metatheory that highlights the importance of humans' evolved inner resources for personality development and behavioral selfregulation" [12]. The theory outlines three innate psychological needs for self-motivation and positive internal processes: the needs for competence, relatedness, and autonomy.

The important element of the SDT is that all three of these needs work in conjunction and would not be effective independently. When all three are working in conjunction, this is when an individual can achieve the greatest sense of well-being, or "eudaimonia” [12]. For example, autonomy increases intrinsic motivation, however intrinsic motivation is more likely to be effective when individuals feel a sense of security through their relatedness with others [12]. Autonomy in educational settings is particularly important, where teachers who support autonomous learning environments improve their students' intrinsic motivation, curiosity and desire for challenge [12].

As all three elements are basic needs, the theory does not "focus on the varying strength of needs but instead focus[es] on concepts resulting from the degree to which the needs have been satisfied versus thwarted" [2]. For example, an activity such as a prescribed lab activity might satisfy competence and relatedness, however it thwarts the need for autonomy. In educational settings, it is important to do our best to engage in activities which best satisfy at least some part of all three needs.

\subsection{Data Collection}

Three artifacts were used for the purpose of this research. Firstly, we analyzed students' final reflections. They were given this reflection assignment on March 22, 2019, which was at the end of the technical content of the course, and before their final 3 weeks which were focused on the project. This reflection included eight open-ended questions such as What is the most important theoretical concept you learned this semester? Why do you think this is so important? and What has been a highlight of this term?

Secondly, we analyzed two of the logbooks from their first semester of third year (i.e. after having participated in the ILS program). These included three open-ended questions, which generally asked about, 1) have you approached your learning differently; 2) has there been any activities you were particularly well prepared for; and 3) have there been activities you struggled with. The logbooks analyzed were from October and November 2019.

\subsection{Data Analysis}

Deductive thematic analysis was used to analyze the student reflections and assignments. We followed Braun and Clarke's method for thematic analysis, which they describe as "a method for identifying, analyzing and reporting patterns within data” [1].

Our approach to thematic analysis is routed in constructionism, in which we aim to report the experience and reality of the participants, which we believe to be socially constructed. With this approach, we can focus on the sociocultural context of the ILS program, and theorize about the structural conditions the program was able to achieve. In our analysis, we mainly focused on semantic themes where we are looking at the words used by participants at their surface meanings, without too much interpretation beyond their meaning [1].

We followed the steps of thematic analysis, as laid out by Braun and Clarke [1]: familiarize ourselves with data; generate initial codes; search for themes; review themes; define and name themes; and produce the report. As we used deductive analysis with the self-determination theory, we also grouped our themes under the categories of competence, relatedness, and autonomy.

\subsection{Ethics Approval}

The research discussed here has been approved by the CFREB (Conjoint Faculties Research Ethics Board) at the University of Calgary. Students consented to have their course data, reflection assignments, feedback surveys and logbook entries included anonymously as part of the research project. From the 34 students in the class, 18 students responded to the survey and gave consent to use their data. 


\section{RESULTS}

From the thematic analysis, there were 11 themes that emerged, categorized within the three elements of the theoretical framework: competence, relatedness, and autonomy. Figure 4 below provides a visual overview of the themes, and Table A.1 in the appendix provides a more detailed summary. In our discussion of the results below, we have included quotes from the student reflections included to illustrate each of the themes.

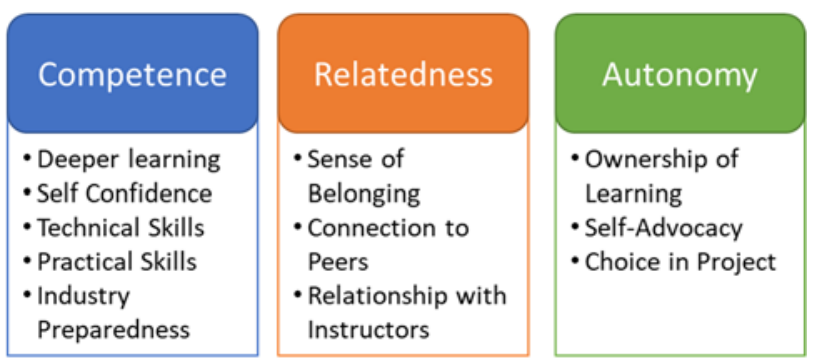

Fig 4. Overview of 11 themes from results, categorized into the three elements of theoretical framework.

\subsection{Competence}

Competence was the most common element of selfdetermination theory across the analysis, with five themes. Some of the themes that emerged are deeper learning, selfconfidence, technical skills, practical skills, and industry preparedness.

5.1.1. Deeper Learning: This theme was most common in the reflections in the student logbooks during their first semester of third year. Looking back, they observed differences in their learning, and how they understood the value of a deeper learning approach. For example, one student said, "I now put more effort into understanding the concept and using that knowledge to think about a problem rather than before when I just used to solve the problems without thinking much."

Students realized that the deeper learning helped them to contextualize the problems, for example, "Knowing where formulas come from, and seeing demonstrations during lectures, has helped me to think more critically about real-life scenarios being modelled by problems on assignments and exams." Students care about their learning beyond just their grades. Another student said that after ILS, in their labs "instead of just rushing through and getting all the data down for marks, I now take my time to understand what's happening and if I don't, I ask someone."

5.1.2. Self-Confidence. While a latent approach to thematic analysis may reveal this theme more prominently, there were still a few explicit statements that showed students gaining confidence in their abilities as a product of participating in this program. For example, one student stated “I am much more ready to jump into hands-on activities, such as circuit analysis using the oscilloscope, without much preparation." Others talked about their accomplishments in the final project really helping them to gain confidence, for example, "The highlight of this semester was getting to work on our audio player project. It was exciting to see our idea come to life."

5.1.3. Technical Skills. In the post-ILS logbooks, students commented on noticing better technical skills in comparison to their peers who did not participate in the ILS program. For example, one student talked about how "we are in a group that has majority ILS students, and in the labs we finish quite a bit earlier than the other groups due to our experience with the instruments and bread-boarding circuits." In their responses to the most important theoretical concept learned during ILS, students could clearly identify a variety of technical skills that aligned with the learning outcomes of the 4 technical courses. Most students provided elaborate and thorough explanations as to why circuit analysis, semi-conductor physics, computer architecture, or signals theory was 1) a skill/knowledge they acquired in the program, and 2) an important skill/knowledge. Some students even recognized these skills as the building blocks of future engineering careers. A few students recognized the concepts that overlapped multiple courses as being the most significant components. For example, they talked about "being able to apply knowledge to more than just one class”.

5.1.4. Practical Skills. In their comments, Students frequently acknowledged improved proficiency with instrumentation (using the equipment), soldering, and using the micro-controller. Comments after the conclusion of the program included: "I definitely feel much more comfortable working with the basic instruments that you will see in a typical lab and am quick to get things set up and running. My troubleshooting skills with the equipment is also more developed," and "I think one of the most practical skills that I learned was building a filter and an amplifier. This is an important skill to learn since this is the most basic part of any circuit that we're going to build in the future."

5.1.5. Industry Preparedness. Not only did the students comment on how the aforementioned technical and practical skills will help them as engineers, they also commented on how the program helped them prepare for interviews: "I feel a lot more prepared when it comes to job interviews because all of the technical questions seem to apply to material we covered in the ILS during the hands-on components of the term." As part of the ILS, students took a few field trips to engineering firms around town. One student commented on how after one such visit, "I realize that these skills will be valuable in industry." 


\subsection{Relatedness}

Some of the themes that emerged were a sense of belonging, closer connection to peers, and forging relationships with the instructional team.

5.2.1. Sense of Belonging. While this was a more subtle theme, there were a few comments that explicitly referenced how the program made the students feel like they belong in electrical engineering. For example, " $I$ believe that the whole term was a highlight. This semester has been the most enjoyable of my university career. It has taught me to be self-reliant, a better team worker, and due to be being able to gain a better relationship with professors, better appreciate the subject of electrical engineering."

5.2.2. Connection to Peers. Because of the class size and the design of the program, students frequently commented on how much closer they felt to their peers in comparison to the classes outside of the program. For example, students talked about their highlight was getting "to know the people in my group as they are all excellent people”. Although there are different models for groupwork, students appreciated their lasting learning community, as "having persistent groups throughout the whole semester was a big help, because it made me feel comfortable asking the stupid questions." The connections made with their peers carried on after ILS, where some students said "in classes I continue to study with most of the members from my learning community."

5.2.3. Relationship with Instructors. For the same reasons as the previous theme, students commented on how their interaction with professors have changed in comparison to their prior courses. Many have stated that they "feel more comfortable reaching out to professors for assistance" and were "less afraid to ask questions or go up and talk about concerns or questions on the material." They also commented on how they are more comfortable in approaching professors after leaving the ILS program. Some students also appreciated the personal connections made with the instructional team. For example, "another huge highlight has been all the close interactions we have with our profs and TAs [Teaching Assistants]. It is rare to know a teacher like we do and it is really cool to say that all my teachers know who I am."

\subsection{Autonomy}

Some of the themes that emerged were ownership of learning, self-advocacy, and positive comments on ability to choose the final project.

5.3.1. Ownership of Learning. Students talked about how the ILS program helped them to develop skills to take ownership of their own learning. One student said, "Since ILS, [...] rather than just sitting there and have content wash over me, I'm trying to take a more active role in my learning." Another student had a similar learning, "This program really taught me the value of doing problems and struggling rather than reviewing lecture material and only doing assignments to study."

Other students talked about the skills they learned to take ownership of their learning, for example "get organized and ask plenty of questions," or learning to be "accountable to yourself." Some students also realized that they were responsible for learning the material, even during labs when they can lean on group members. One student said, "Sometimes my groupmates would kind of take over the lab making me feel useless, and then leading to me not learning anything in the lab.” They had started to recognize when this was happening, and they wanted to take more ownership during labs, to support their own learning and success.

Students also mentioned how the flipped learning format of some of the courses in ILS helped them to take ownership, by saying "The biggest help for me was the flipped classroom style of teaching. For me it helped me learn at the rate and time that I wanted." Overall, there were many elements of ILS that helped students to learn the necessary skills and importance of taking ownership of their learning.

5.3.2. Self-Advocacy. Throughout the ILS program, we were continuously asking for feedback from the students. Because of this, they learned to advocate for their learning and provide consistent and useful feedback. For example, one student said after the long lectures, "I understood less sometimes after I finished a lecture then when I went in as my brain was just fried!"

Another student said that "One of the things that can be improved is better scheduling for the classes. Maybe they can try to space out the classes since I feel like our schedule right now is very packed." It is evident that through these pieces of feedback, the students are not just complaining, but rather they are advocating for what is best for their own learning.

5.3.3. Choice in Project. This theme was less common in the analyzed reflections, however there were still a few comments which shows that students really appreciated the autonomy they had through the choice of their project. For example, one student said, "Being able to work on a big project and come up with ideas on our own has been really fun and challenging, and has been a great way of putting all the concepts we've learned into practical use."

\section{DISCUSSION AND CONCLUSIONS}

The self-determination theory shows us how to support student motivation through fostering competence, relatedness, and autonomy. In the ILS, we have been designing the courses, the assessments, the student community, and the physical space to foster these. In terms of competence, the students had $24 / 7$ access to the 
measurement, design, and test equipment. The Makerspace Multiplex in the engineering building gives the students access to 3D printing and technicians who could help them with their design projects. During the instructional hours, students had easy access to instructors and teaching assistants. These factors along with the design of the course and the project increased their competence. The agile project management style practiced in the design course gave the students the ability to build rapid prototypes and test their ideas thereby increasing their competence.

The learning communities and the physical layout of the room, as well as the discussion sessions between the professors and the students increased the sense of relatedness. In addition, designing a product for real world application gave the students the opportunity to relate the course material to an actual problem.

The sense of autonomy was developed through giving students the freedom to choose their design product, and by using flipped classrooms.

All of the above increased the students' intrinsic motivation to study and improved their learning outcomes.

The next steps for the ILS program are to increase the number of students in the class as well as designing methods to reduce the required resources in terms of instructional personnel and space.

\section{References}

[1] Braun, V., \& Clarke, V. (2006). Using thematic analysis in psychology. Qualitative research in psychology, 3(2), 77101

[2] Deci, E. L., \& Ryan, R. M. (2008). Self-determination theory: A macrotheory of human motivation, development, and health. Canadian psychology / Psychologie canadienne, 49(3), 182.

[3] Everett, L. J., Imbrie, P. K., \& Morgan, J. (2000). Integrated curricula: Purpose and design. Journal of Engineering Education, 89(2), 167-175.
[4] Fogarty, R. (1991). Ten ways to integrate curriculum. Educational leadership, 49(2), 61-65.

[5] Froyd, J. E., \& Ohland, M. W. (2005). Integrated engineering curricula. Journal of Engineering Education, 94(1), 147-164.

[6] Honey, M., Pearson, G., \& Schweingruber, H. A. (Eds.). (2014). STEM integration in K-12 education: Status, prospects, and an agenda for research (Vol. 500). Washington, DC: National Academies Press.

[7] Kelley, T. R., \& Knowles, J. G. (2016). A conceptual framework for integrated STEM education. International Journal of STEM Education, 3(1), 11.

[8] Kysilka, M. L. (1998). Understanding integrated curriculum. Curriculum journal, 9(2), 197-209.

[9] National Academy of Engineering and National Research Council [NAE \& NRC].(2014).STEM integration in K-12 education: Status, prospects, and an agenda for research. Washington: National Academies Press.

[10] Olds, B. M., \& Miller, R. L. (2004). The effect of a firstyear integrated engineering curriculum on graduation rates and student satisfaction: A longitudinal study. Journal of Engineering Education, 93(1), 23-35.

[11] Reeve, J. (2002). Self-determination theory applied to educational settings. In E. L. Deci \& R. M. Ryan (Eds.), Handbook of self-determination research (p. 183-203). University of Rochester Press.

[12] Ryan, R. M., \& Deci, E. L. (2000). Self-determination theory and the facilitation of intrinsic motivation, social development, and well-being. American psychologist, 55(1), 68.

[13] Theories of Motivation (2012). In Organizational Behavior v.1.1. (2012) Saylor Academic. Retrieved February 9, 2020 from https://saylordotorg.github.io/text_organizationalbehavior-v1.1/s09-theories-of-motivation.html 